2. Tagaya N, Mikami H, Kogure H, Kubota K, Hosoya Y, Nagai H. Laparoscopic intragastric stapled resection of gastric submucosal tumors located near the esophagogastric junction. Surg Endosc. 2002;16:177-9.
3. Conrad C, Nedelcu M, Ogiso S, Aloia TA, Vauthey JN, Gayet B. Laparoscopic intragastric surgery for early gastric cancer and gastrointestinal stromal tumors. Ann Surg Oncol. 2014;21:2620.

\title{
Complications of intrathoracic lines placed during cardiac surgery
}

\author{
Himanshu Pratap, MS, MBBS, ${ }^{a}$ Johnny Millar, MBChB, PhD, ${ }^{\mathrm{b}}$ Warwick Butt, MBBS, ${ }^{\mathrm{b}, \mathrm{c}, \mathrm{d}}$ and \\ Yves d'Udekem, MD, PhD, ${ }^{\mathrm{a}, \mathrm{b}, \mathrm{d}}$ Melbourne, Victoria, Australia
}

See related commentary on page 1214 .

Intracardiac catheters are frequently used in pediatric patients for monitoring intracardiac pressures and to provide vascular access. Data are scarce on the incidence of complications related to use of such catheters. ${ }^{1-3}$

Since January 2005 , all health data for patients transiting the intensive care unit of the Royal Children's Hospital (Melbourne, Australia) have been entered into our database

From the Department of Cardiac Surgery, ${ }^{\text {a }}$ The Royal Children's Hospital, Melbourne; Department of Pediatrics, ${ }^{\mathrm{b}}$ University of Melbourne, Melbourne; Paediatric Intensive Care Unit, ${ }^{\mathrm{c}}$ The Royal Children's Hospital, Melbourne; and Murdoch Children's Research Institute, ${ }^{\mathrm{d}}$ Melbourne, Victoria, Australia.

This research project was supported by the Victorian Government's Operational Infrastructure Support Program.

Disclosures: Yves d'Udekem is a Career Development Fellow of The National Heart Foundation of Australia (CR 10M 5339) and National Health and Medical Research Council Clinician Practitioner Fellow (1082186). All other authors have nothing to disclose with regard to commercial support.

Received for publication July 23, 2014; revisions received Nov 3, 2014; accepted for publication Nov 28, 2014; available ahead of print Jan 13, 2015.

Address for reprints: Yves d'Udekem, MD, PhD, Department of Cardiac Surgery, Royal Children's Hospital, Flemington Rd, Parkville, Melbourne, Victoria 3052, Australia (E-mail: yves.dudekem@rch.org.au).

J Thorac Cardiovasc Surg 2015;149:1212-3

$0022-5223 / \$ 36.00$

Copyright (C) 2015 by The American Association for Thoracic Surgery

http://dx.doi.org/10.1016/j.jtcvs.2014.11.082 for that unit, with 1 entry being devoted to the following catheter line-related complications: migration (inadvertent extrusion of the line outside its desired location) or premature removal (earlier than planned removal); bleeding after line removal (unexpected drain output or substantial pericardial collection after planned line removal); line occlusion (absent waveform tracings); thrombosis (echocardiographic demonstration of thrombus in the cardiac chamber containing the line); and failed removal. The files of all patients recorded as having a line-related complication were reviewed.

Left atrial (LA) and right atrial (RA) lines were inserted through their respective appendages and secured with 2 purse-strings of Prolene 6-0 (polypropylene) (Covidien, Mansfield, Mass) placed around the entry point of the line, with the addition of a silk suture per surgeon preference. To avoid migration of the RA lines, 1 surgeon additionally secured the line by looping the ends of the purse-string suture along the extracardiac portion of the line and tying it off near the entry point. The other 2 surgeons left a long loose segment of lines between the entry in the chest and the insertion in the RA appendage (Figure 1).

Right atrial lines were pediatric multilumen central venous catheters (Arrow International, Inc, Reading, Pa); LA lines were polyurethane umbilical vessel catheters (Tyco Healthcare Group LP, Mansfield, Mass). Pressure catheter placement sets (Medtronic, Inc, Minneapolis, Minn) were used as

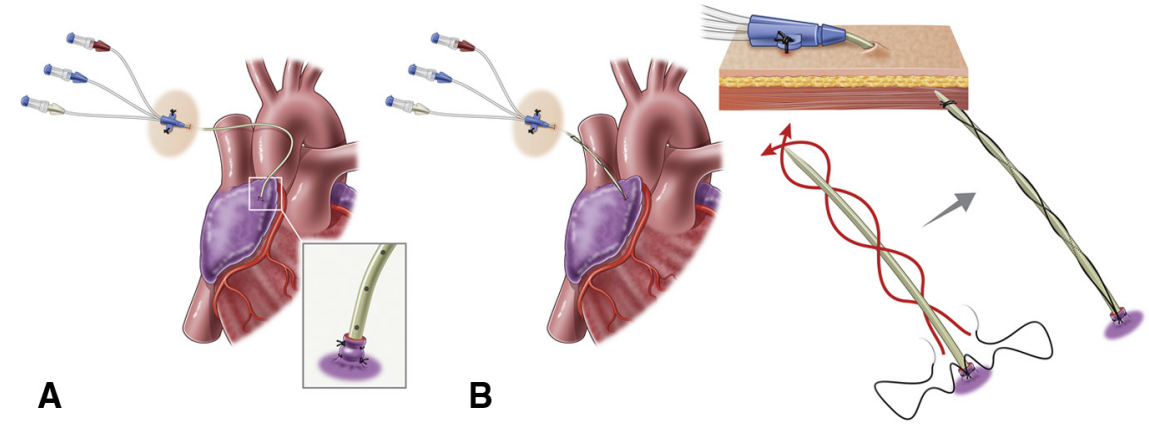

FIGURE 1. Techniques of insertion of a direct right atrial line to prevent the line from being pulled off by lung inflation. A, A long loop is left on the line before the entry point into the right atrium. B, A 7-0 polydioxanone suture is secured between the entry point of the line into the skin and its entry point into the right atrium. 
TABLE 1. Line usage and complications

\begin{tabular}{lcccc}
\hline \multicolumn{1}{c}{ Complication } & $\begin{array}{c}\text { LA line } \\
(\mathbf{n}=\mathbf{7 2 4})\end{array}$ & $\begin{array}{c}\text { PA line } \\
(\mathbf{n}=\mathbf{4 1 3})\end{array}$ & $\begin{array}{c}\text { RA line } \\
(\mathbf{n}=\mathbf{2 6 7})\end{array}$ & $\begin{array}{c}\text { Total } \\
(\mathbf{n}=\mathbf{1 4 0 4})\end{array}$ \\
\hline $\begin{array}{l}\text { Migration and/or } \\
\quad \text { premature removal }\end{array}$ & 2 & 3 & 12 & 17 \\
$\begin{array}{l}\text { Bleeding } \\
\text { Thrombosis }\end{array}$ & 2 & 2 & 0 & 4 \\
Occlusion & 0 & 1 & 3 & 4 \\
Failed removal & 1 & 1 & 2 & 4 \\
Total & 1 & 0 & 0 & 1 \\
\hline
\end{tabular}

For total, values are $\mathrm{n}(\%)$; all other values are $\mathrm{n} . L A$, Left atrial; $P A$, pulmonary artery; $R A$, right atrial.

pulmonary artery (PA) lines; they were inserted through the pulmonary infundibulum and secured by 1 or 2 pledgeted sutures placed around the entry point of the line.

As a blanket policy, all patients in the intensive-care unit were maintained on continuous infusion of heparin at 10 units $/ \mathrm{kg} /$ hour until line removal, without any targeted anticoagulation level. The center policy was to remove lines on postoperative day 4 , unless the lines were still in use or the coagulation profile of the patient was impaired. Heparin infusion was stopped 4 hours before removal of lines. After line removal, a focused echocardiography study was always performed to screen for any mediastinal bleeding.

Between 2005 and 2013, a total of 1404 intracardiac lines were inserted in 1118 patients: 224 (20\%) patients had 2 lines, and $31(2.7 \%)$ patients had 3 lines. Ninety-four $(8.4 \%)$ patients were newborn (underwent operation on the first day of life), and $464(41.5 \%)$ were neonates (aged $\leq 28$ days). Direct RA lines were systematically inserted during the first procedure for a single-ventricle palliation pathway, to avoid damage to the superior vena cava. PA and LA lines were inserted selectively when the possibility that the patient might display elevated measurements was anticipated. We documented 30 $(2.1 \%)$ instances of complications directly attributable to these lines (Table 1). No line-related deaths occurred.

\section{MIGRATION AND/OR PREMATURE REMOVAL}

Migration of RA lines occurred in 12 of 267 line insertions $(4.4 \%)$, necessitating a return to the operating room in 5 cases. In 2 of these 5 cases, sudden bleeding occurred after Norwood surgery and necessitated extracorporeal membrane oxygenation support. Five of these 12 migrations occurred in patients for whom the technique of using the extra securing of the line was applied (Figure 1). Two of the 724 LA lines $(0.2 \%)$ migrated, with 1 necessitating a reoperation for bleeding. A PA line was prematurely removed in 3 instances: once because of a crack in the line hub, once because entrapped air was identified in the line, and once for an unidentified reason.

\section{BLEEDING AFTER LINE REMOVAL}

Significant bleeding after planned removal was identified in 2 LA and 2 PA lines by echocardiography. The bleeding was managed conservatively in 2 cases and necessitated reintervention in 2 cases, including extracorporeal membrane oxygenation support in 1 case before the patient reached the operating area.

\section{SURGICAL INTERVENTION FOR LINE-RELATED COMPLICATIONS}

Altogether, 9 of $1404(0.8 \%)$ cases required surgical interventions, including extracorporeal membrane oxygenation support in 3 cases $(0.3 \%)$. Eight of these interventions were for life-threatening bleeding, and 1 was to retrieve a retained LA line.

A total of $8(0.6 \%)$ patients required intervention for bleeding (6 after line migration and 2 after line removal). This rate is higher than the one quoted in a historical series $^{2}$ from 1986, and lower than a more recent estimate. ${ }^{1}$ Flori and colleagues ${ }^{1}$ demonstrated in this latter study that younger age is a risk factor for reintervention after insertion of an intracardiac line. Our series included younger patients than the ones in the historical series, ${ }^{2}$ which likely explains our higher rate of bleeding. We encountered less bleeding from LA lines than was found in the series by Flori and colleagues, ${ }^{1}$ a difference that may be related to the fact that they inserted these lines in the junction between the right pulmonary veins and the atrium. ${ }^{1}$ We believe that more complications were encountered with RA lines than with LA and PA lines because of the thinner wall and higher fragility of the right atrium.

In conclusion, the use of intracardiac lines is safe. In rare instances, it can result in dramatic bleeding and reintervention. The RA lines are more at risk of migration than the LA and PA lines.

\section{References}

1. Flori HR, Johnson LD, Hanley FL, Fineman JR. Transthoracic intracardiac catheters in pediatric patients recovering from congenital heart defect surgery: associated complications and outcomes. Crit Care Med. 2000;28: 2997-3001

2. Gold GP, Jonas RA, Lang P, Elixson M, Mayer JE, Castaneda AR. Transthoracic intracardiac monitoring lines in paediatric surgical patients: a ten year experience. Ann Thorac Surg. 1986;42:185-91.

3. Wheedon D, Shore DF, Lincoln C. Continuous monitoring of pulmonary artery pressure after cardiac surgery in infants and children. J Cardiovasc Thorac Surg. 1981;22:307-11. 